\title{
UNUSUAL SUICIDE CASE: SURVIVED AFTER LONG SUFFERING
}

\author{
ARFA RAHMAN ${ }^{1}$, HOMAYRA TAHSEEN ${ }^{2}$,QUAZITARIKUL ISLAM ${ }^{3}$, HAM NAZMUL AHASAN $^{4}$
}

\begin{abstract}
Hanging is one of the common forms of violent mechanical asphyxial death. When compared to other forms of unnatural death all over the world this method stands on top as death is instantaneous. Hanging is always suicidal unless otherwise proved. The aim of this study is to gain new knowledge that would enable the design of effective of measures that would help to prevent suicide by hanging. In this case report, we will discuss the unusual presentation of a young lady who attempts suicide frequently did not result in death. We present data indicating that victims can be resuscitated even after prolonged period of suspension \& unconsciousness \& some of the reasons why asphyxiation by hanging may be delayed when there is no damage to the spinal cord. The logical, thoughtful management options that we chose at various stages of her disease in general ward with the use of colistin which eventually led to her cure are also discussed here. Emphasis is given on how these tricky cases can be deal with prognostically good results could be achieved, if such victims are vigorously \& promptly resuscitated, irrespective of her initial presentation.
\end{abstract}

Keywords:Hanging, Suicide, Asphyxiation, Neurogenic Shock, Aspiration pneumonia, survival,termination of resuscitation, colistin, prevention

Received: 07 October, 2020

Accepted: 25 December, 2020

DOI: https://doi.org/10.3329/bjm.v32i1.51095

\section{Introduction}

Hanging is one of the commonest Method of suicideBangladesh. In Switzerland, it is the most frequent suicide method. The lethality of hanging is between $69 \%$ and $84 \%$ \& thus only slightly lower than the lethality of shooting. In addition, there has been a general increase over time in hanging as a method of suicide. Hanging or self-suspension is a form of ligature strangulation where the pressure is produced by the weight of the body itself. It is almost invariably suicidal except in some masochistic accidental cases.

Hanging is a form of asphyxia which is caused by suspension of the body by a ligature which encircles the neck, the constricting force being weight of the body, whole weight is not necessary. Weight of the head ( $5 \mathrm{~kg}-6 \mathrm{~kg}$ ) is enough to act as constricting force. So, death happens in partial hanging also, which are on toes, feet, touching, sitting, kneeling \& lying down postures. Hanging produces painless death for the victims $\&$ there is no costs involvement other than that of the ligature material. A thin rope around the neck will cause unconsciousness in 15 seconds. Over one million people die by suicide worldwide each year. 1.8\% of worldwide deaths are suicide.

Passion, disappointment, loss of property, misfortune, financial losses, poverty, disgust with life, physical \& mental sufferings, religious mania, unhappy love, failures in many aspects, marital problems, jealous, unbearable fear $\&$ pain are some of the common known reasons for hanging. There will vary widely from country to country, between religions $\&$ socio-economic classes. Marital problem is the leading cause in developing countries like Bangladesh. A suicide victim will use any article readily available for the purpose i.e. saree, dhoti, rope, towel, bed sheet, chains, wiresthis factors that lead the suicide victim to hang themselves. There are significant differences in hanging between men \& women.

1. Asstt. Registrar of Medicine, Popular Medical College

2. Associate Professor of Medicine, Popular Medical College Hospital

3. Professor of Medicine, Popular Medical College

4. Professor of Medicine, Popular Medical College

Address of Correspondence: Dr. Arfa Rahman, MBBS, Asst. Registrar of Medicine, Popular Medical College, Email: arfarahmanava@gmail.com

Bangladesh J Medicine 2021; 32 : 53-57 
In general, men tend to choose more violent means than women. Although hanging is common across the world, survival after attempted hanging is very rare with death usually occur within minutes or over the first 24 hours. If the person who survives via hanging attempts, whether due to breakage of the cord, or ligature point, or being discovered $\&$ cut down, face a range of serious injuries, including cerebral anoxia (which can lead to permanent brain damage \&later may die because of the severity of the initial hypoxic and ischemic brain damage), laryngeal fracture, cervical spine fracture (which may cause paralysis), subluxation of C2 \& C3 vertebra, tracheal fracture, pharyngeal laceration \& carotid artery injury. In the absence of fracture \& dislocation, occlusion of blood vessels becomes the major cause of death, rather than asphyxiation. Obstruction of the venous drainage of the brain via occlusion of the internal jugular veins leads to cerebral edema \& then cerebral ischemia. Survival from hanging is often associated with various complications including a large variety of neurological consequences. The first goal of this study is to improve our comprehensive of the medical \& sociodermographic variables within the group of people who hang themselves. Based on our findings, we make suggestions to improve suicide prevention measures.

\section{Case Report}

A 31-year-old, normotensive, non-diabetic female, brought to emergency department of a local clinic after she was found hanging from ceiling fan tied by a lady'sgauze scarf. The duration was hanging was not known. But the time to the nearest clinic approximately 30 minutes. Her husband was around but not in the same room\& the door was left slightly open. Upon witnessing the incident at around $2: 30 \mathrm{pm}$ on $19^{\text {th }}$ September 2020, he immediately lifted her up \& cut the lady's gauze scarf. Her Husband untied the knot thereafter which was placed laterally in front of neck. Her husband was also performed CPR (Cardiopulmonary Resuscitation) after which her respiration initiated. At the same time developed cyanosis of fingertips $\&$ nail beds of both hands. On Arrival to the local clinic, she was unconscious with tongue slightly protruded \& frothy secretions from mouth, Partial ligaturemark was noted around her neck \& there was no subconjunctival hemorrhage and GCS(Glasgow Coma Score) was 4, on examinationpupils were sluggish reactive to light and partially dilated. Later, she was admitted to the ICU(Intensive care unit) department. The qualified personal resuscitated the patient, stabilized the neck by cervical collar \& airway secured by Intubation. In ICU setting,
Arterial Blood Gas (ABG) Analysis performed, reveals Respiratory Acidosis $\left(\mathrm{P}^{\mathrm{H}} 7.25\right.$ \& Paco2 50 mm Hg).Her oxygen requirement gradually increased. She was put on assisted Mechanical Ventilation for 1 days.

On admission, her pulse rate 116 beats $/ \mathrm{min}$, Blood pressure 80/50 mmHg, SPO2 95\% with 10LO2, pupil partially dilated. As her condition deteriorating, so shifted the patient another hospital ICU\&Tracheostomy was done in situ of the patient.Her tracheostomy tube sometimesblocked by mucopurulent secretions in and around the tube, so tracheostomy tube changed. At the same time nasogastric feeding \& total parenteral nutrition was given. After evaluation, she was found to have neurogenic shock which required dopamine with combination of vasopressor (Norepinephrine) agents. She also developed aspiration pneumonia. Eventually, shock resolved \& patient could maintain blood pressure without any support. Weaning trial tried but failed as there was slow progression of her conscious level, she required airway protection. She was on Assisted Ventilation for 15 days. With improvement in chest condition \& reduction in $\mathrm{FiO} 2$ support thereafter, weaning off assisted ventilation was gradually commenced $\&$ the patient was extubated when she regained spontaneous respiratory efforts $\&$ didn't require any mechanical ventilation. Her tracheostomy tube became blocked several times. So, recheck of the tracheostomy tube $\&$ got changed again. She developed convulsions \& still continues to suffer such insults.

As her clinical conditions day by day deteriorating, her husband decided to get admitted Popular Medical College Hospital for further management. Admitted with the complaints, fever for 6 days and altered level of consciousness. Her recorded temperature was $104^{\circ} \mathrm{F}$ which was associated with chills and rigors \& relieved by taking antipyretics (Fig 1). Meanwhile, fever peaked at $103 \mathrm{~F}$ was associated with marked tachycardia. On query, her husband mentioned she was depressive $\&$ tried to attempt suicide quite few times. She didn't require any oxygen intervention but when hertracheostomy tube become blocked leads to respiratory distress and become restless. She advised for avoid left lateral position, preferable right lateral, right semi-prone, prone position.

On Examination, she was ill-looking, restless, lean \& thin, semiconscious, Anemia- mild, pulse 138 beats/ min, Blood pressure 110/70 $\mathrm{mmHg}$, Respiratory rate 28 breath $/ \mathrm{min}$, Temperature $102^{\circ} \mathrm{F}$, SPO2 96\% at room air, GCS - E3V2M2, Bilateral planter extensor noted.

Baseline Investigations were done, Her Complete Blood 


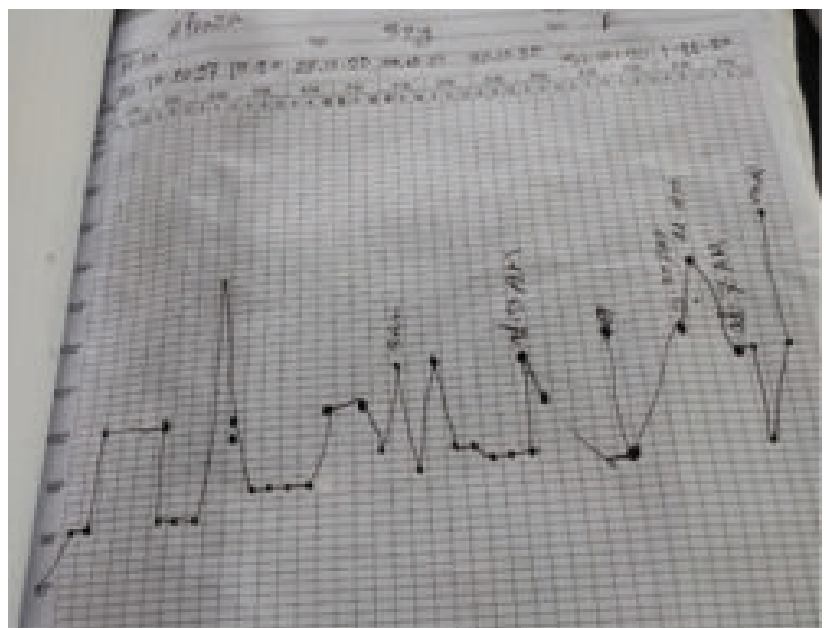

Fig.-1: Temperature chart

Count shows Neutrophilic Leukocytosis $\left(15.34 \mathrm{k} / \mathrm{mm}^{3}\right)$, $\mathrm{Hb} 8.4 \mathrm{gm} / \mathrm{dl}$, ESR $84 \mathrm{mmHg}$ in $1^{\text {st }}$ hour, CRP - Raised (108 mg/L), Serum Electrolytes - Sodium: 136 \&Potassium: $2.85 \mathrm{mmol} / \mathrm{LDone}$ on 27 October,2020 $\&$ S. Procalcitonin -0.10 ng/ml(Normal), Lactate 11.20(Normal), S. Creatinine $0.57 \mathrm{mg} / \mathrm{dl}$ (Normal), Blood Urea-20 mg/dL(Normal).Others - S. Calcium, S. Magnesium, S. Albumin were within normal limit.

As her fever was not subsided, to proper evaluation of cause done some Investigations:

1. Urine $\mathrm{R} / \mathrm{M} / \mathrm{E}$ : microscopic examination- RBC 20/ HPF \& Pus cell 6-8/HPF

2. Urine $\mathrm{C} / \mathrm{S}$ : Growth of Klebsiella pneumoniae $\left(1 \times 10^{\wedge} 3\right)$

3. Blood C/S- No growth

4. Tracheal Aspirate C/S:Colony count moderate (Organism: Klebsiella pneumoniae) (Sensitive to Colistin, Imipenem, Meropenem)

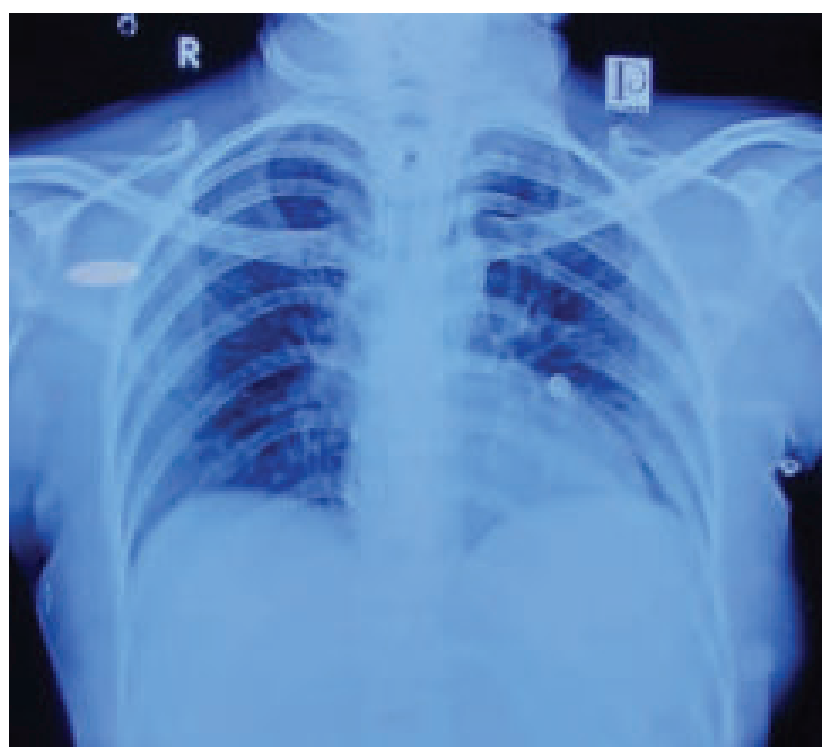

Fig.-2: $C X R P A$ View:
As her fever still not subsided so repeat culture sensitivity of tracheal aspiration done to find out the drug sensitivity:Profuse (Organism: Acinetobacter Species)

(Sensitive to Piperacillin-Tazobactam, Ceftazidime, Cefepime, Aztreonam)

Chest X-Ray reveal bilateral opacities in both lungfields (more chances of aspiration pneumonia)(Fig :2). As patient semiconscious, disoriented, MRI of brain which shows bilateral hemispherical cortical necrosis sequelae of hypoxic ischemic changes (Fig:4) To evaluate any injury to neck structures, spiral CT scan of maxillofacial region with neck revealed there were no injury to hyoid bone \& thyroid cartilage (Fig:3) On the basis of cultural sensitivity of tracheal aspiration, first Piperacillin+Tazobactamand and Amikacin combination used for few days. As her condition still not improving at last Colistin is used \& dramatic improvement of her clinical condition, fever subsided $\&$ aspiration pneumonia improved. Therewere several convulsive episodes observed. EEG (Electroencephalogram) performed which revealed normal \& got some prophylactic anticonvulsant medication.

Patient general condition quite improving except psychological distress. It required long time period to recover. The median time of good recovery of this patient around 3 months $\&$ patient still now admitted $\&$ become managed in general ward. Advised her mother,we could discharge her as good recovery.

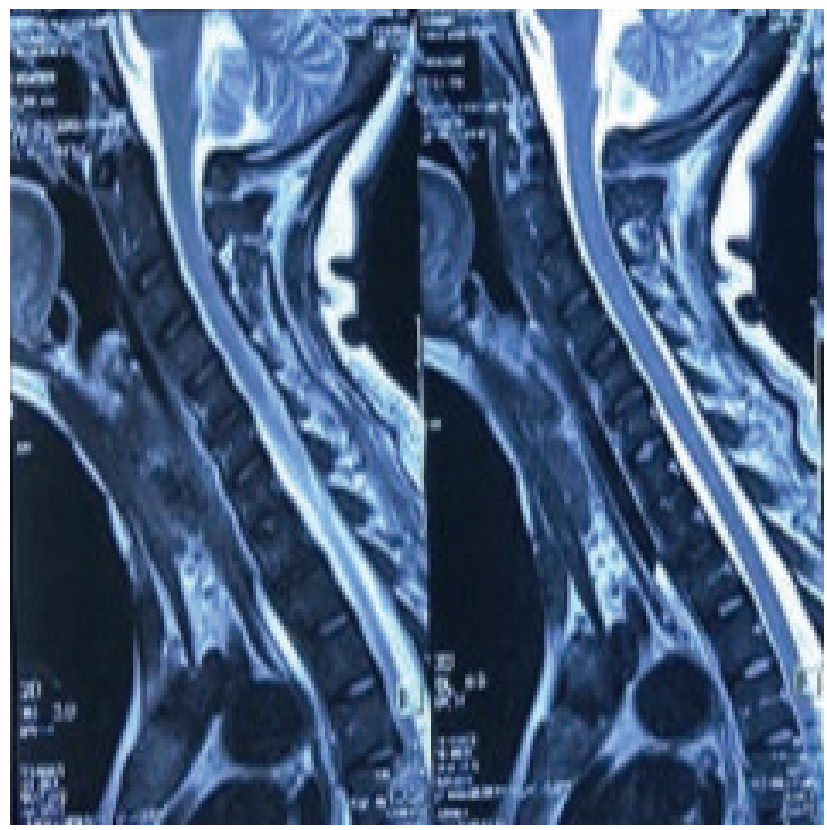

Fig.-3: CT scan of maxillofacial region with neck (spiral ct neck) findings:

1. No cervical injury.

2. No bony lesion.

3. No injury to hyoid bone.

4. No injury to thyroid cartilage. 

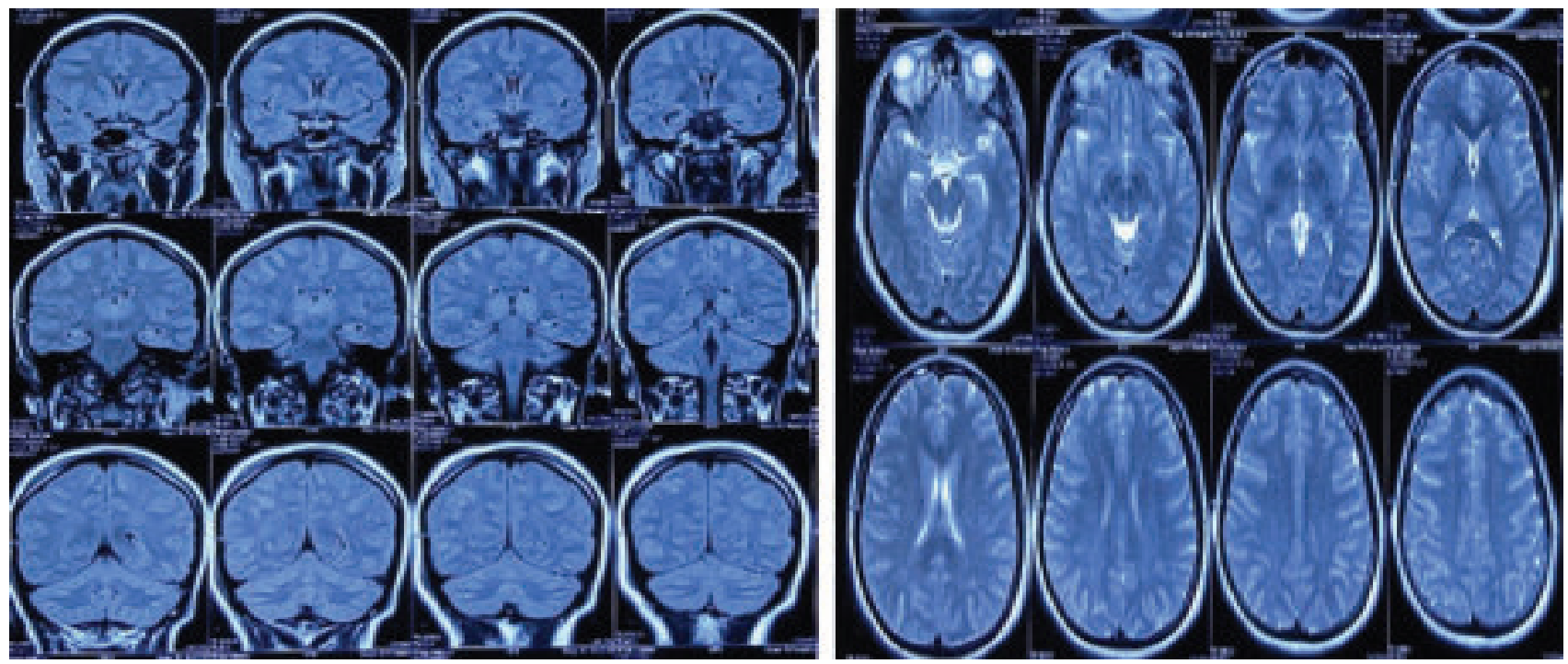

Fig.-4: MRI of brain:

Bilateral opacities present in both lung fields Particularly middle zone of left side (chances of aspiration pneumonia)

Bi-Hemispherical laminar cortical necrosis (evolving global hypoxia) sequelae to hypoxic ischemic episodes, extended lesions involving bilateral thalamus.

\section{Discussion}

Manifestations of Hanging include ligature markings in around the neck, tools utilized on the scene lady's gauze scarf or belts, ropes, \& cords; facial/ subconjunctival petechiae; retinal/scleral hemorrhage, Cyanosis of fingertips \& nail beds of both hands \& dribbling marks of saliva. These findings are the most important signs of asphyxia.However, some of its complications can be a surgical issue. These complications are respiratory asphyxia (due to aspiration pneumonia), tracheal stenosis, scarring of neck tissue, interruption to cerebral blood flow because of occlusion of vessels in the neck, the carotid arteries maybe lacerated or avulsed and traumatic decapitation may occur. Spinal cord \& skeletal injuries are rare. Local neck compression may cause venous obstruction \& stagnant cerebral hypoxia. Carotid artery occlusion may occur with consequent ischemic brain injury $\&$ cardiac inhibition secondary to nerve stimulation. Our patient presented to us, bilateral hemispherical laminar cortical necrosis (evolving global hypoxia) sequelae of hypoxic ischemic changes on MRI of brain. Chest radiogram shows suggestive of pulmonary involvement with aspiration pneumonia was also a significant predictor of poor outcome.Following external stabilization of the neck, nasal or oral endotracheal intubation is appropriate emergency airway management in hanging victim.Acute management of hanging should focus on airway protection followed by detailed imaging of the head \& neck. Previous studies have also shown that the mortality increased from $5 \%$ to $34.2 \%$ in the presence of pulmonary involvement. Suicide is a public health problem too often neglected byresearchers, health policy makers $\&$ the medical profession.In our study most of the suicidal hanging cases were found in age group of 2130 years. An individual has to face various sorts of struggle of life with emotional, financial, familial or other crises. We found sensitivity to colistin on tracheal aspiration culture study. The beauty of this case lies in the logical courage to manage the patient, physician in ideal time made correct decision about tracheostomy \&rescued the young female life along with expert opinions from multiple experienced consultants, helped us combat this problem \& we could discharge her.

Suicide data by WHO also mentions that suicide occurs throughout the lifespan and is the second leading cause of death among 15-29 years old globally. Worldwide suicide death rate is higher in males. In UK suicide is three to four times more common in men than in women of any age group.Review of data of 56 countries found that hanging was the most common method in most of the countries, accounting for $53 \%$ of the male suicides $\&$ $39 \%$ of the female suicides. On the contrary suicide rate is higher in women in Bangladesh. suicidal hanging was more common among females in this study. The ratio of suicide is estimated to be 17 -fold higher in rural than in urban areas in Bangladesh. The average rate of female attempted suicides(161/ $100,000)$ was higher thanthe malerate (112/ $100,000) \&$ female suicides $(20.60 / 100,000)$ were also 
higher than male suicides(17.20/100,000). These results support the high rates of femalesuicides that have been estimated documentby several studies in Bangladesh (e.g. alonge et al.,2013; Arafat, 2019a, Bagley et al.,2017). Due to inequity of gender, familial $\&$ social oppression, marital disharmony, lack of economic freedom, early marriage, low literacy, sexual abuse $\&$ such cultural factors.

The high incidence of suicidal hangings among young adult imposes a huge socioeconomic burden on our society. Social awareness for marital unhappiness, legal action for dowry harassment \&proper employment facilities for the youth are required for primary and secondary prevention of suicidal hangings. Active psychiatric intervention is required for those survived from suicidal attempt and also for vulnerable group of people. Further well designed and large-Scale studies are required to look deeply in to the risk factors and formulate preventive measures of suicidal hanging. Another important issue beyond assessing and diagnosing the survivors of suicidal hanging presenting with neuropsychiatric sequelae is provision of social welfare benefits which will again depend on proper assessment and diagnosis.

\section{Conclusion}

We selected this case for publication to highlight some important issues.As we know hanging is a common mechanism of self-harm.After long suffering, she rescued \& we could discharge her. Appropriate education, influencing the media in their portrayal of suicidal news,involvement of young generations in encouraging activities may reduce the rate of suicidal death by hanging in nature.

\section{References}

1. ThomasReisch, Chantal Hartmann, A Hemmer, C Bartsch: Suicide by hanging - Results from a national survey in Switzerland and its implications for suicide prevention;PloS one 14(9), 2019. https://doi.org/ 10.1371/journal.pone.0220508 PMid:31532773 PMCid:PMC6750587

2. Asma Begum, NashidTabasum khan, AKM Shafiuzzaman, Farhana Shahid, AM Ashraful Anam: Suicidal Death Due to Hanging, 5(2),2017,91-92 https:/ /doi.org/10.3329/dmcj.v5i2.33347

3. J Aneja, S Jangli, P Kulhara. Neuropsychiatric Sequelae of Attempted Hanging \& diagnostic dilemmas; Industrial Psychiatry Journal 26(2), 239, 2017 https://doi.org/ 10.4103/ipj.ipj_46_15 PMid:30089976 PMCid:PMC 6058448

4. Changal HK, Raina AH, Parray MA, Allai MS. Attempted Suicidal Hanging leading to hypoxic ischemic encephalopathy. Int J Med Health Sci. 2013;2:376-81
5. Hsu Ch, et al. J Trauma Acute Care Surg. Outcome of Suicidal Hanging Patients and The role of targeted temperature management in Hanging Induced Cardiac Arrest,2017 https://doi.org/10.1097/TA.000000000 0001281 PMid:27787437

6. Valerie J Callanan, Marks S Davis: Gender Difference in Suicide Methods. Social psychiatry \& psychiatric epidemiology; 47(6), 857-869, 2012 https://doi.org/ 10.1007/s00127-011-0393-5 PMid:21604180

7. Wu KC, Chen YY, Yip PS. Suicide Methods in Asia: Implications in Suicide Prevention. Int $\mathrm{J}$ Environ Res Public Health. 2012;9:1135-58 https://doi.org/ 10.3390/ijerph9041135 PMid:22690187 PMCid:PMC 3366604

8. B Runeson, D Tidemalm, M Dahlin, P Lichtenstein: Method of attempted of Suicide as predictor of subsequent successful Suicide: National Long-Term cohort study; BMJ 341, c3222,2010 https://doi.org/ 10.1136/bmj.c3222 PMid:20627975 PMCid:PMC 2903664

9. LenkaZátopková, Martin Janik, Petra Urbanová, JitkaMottlová, Petr Hejna: Laryngo-hyoid fractures in suicidal hanging: A prospective autopsy study with an updated review and critical appraisal; Forensic Science international 290,70-84, 2018 https://doi.org/ 10.1016/j.forsciint.2018.05.043 PMid:30015282

10. Powell J. Suicide is a gender issue that can no longer be ignored(Internet) 2013 Jan 23 (cited 2016 May 22). Available from: http://www.theguardian.com/ commentisfree/2013/jan/23/suicide-rates-mengender-issue

11. Arafat SMY. Suicide in Bangladesh: A mini Review. J Behav Health. 2017;6(1):66-69 https://doi.org/ 10.5455/jbh.20160904090206

12. Knight B. Simpson's Forensic Medicine. 11thedi. London: Arnold; 1997

13. Nadesan K. Pattern of suicide: a review of autopsies conducted at the university hospital, Kuala Lumpur Malays J Pathol. 1999 ; 21: 95-9

14. Bastia BK, Kar N. A psychologicalAutopsy study of Suicidal Hanging from Cuttack, India: Focus on Stressful Life Situations. Archives of Suicide Research. 2009; 13(1): 100-104 https://doi.org/10.1080/ 13811110802572221 PMid:19123113

15. Hossain M N, Rahman Z, Akhter S. Suicidal Death Autopsy Analysis at Dhaka Medical College. Bangladesh Med J. 2011; 40: 18-20 https://doi.org/10.3329/ bmj.v40i1.9957

16. ICDDR, B. Mortality Due to Suicide in Rural Bangladesh. Health and Science Bulletin. 2003;1(5):71017. O' Connor R C, Stephen P, Jacki G, editors. International Handbook of Suicide Prevention:

17. O' Connor R C, Stephen P, Jacki G, editors. International Handbook of Suicide PreventionResearch, Policy and Practice. New York: John Wiley and Sons;2011. p. 3 